\title{
EULAR 2015
}

\section{Gicht - Hohe Harnsäurewerte treiben die Kosten hoch}

\author{
Mit steigenden Harnsäurewerten steigen die Gesundheitskosten, vor allem durch Krankenhauseinweisungen. \\ Eine Harnsäuresenkung mit Febuxostat könnte Kosten sparen.
}

\begin{abstract}
Die Prävalenzen von Hyperurikämie und Gicht nehmen kontinuierlich zu. So stieg die Gicht-Prävalenz etwa in Italien von 0,7 (2005) auf 0,9 Prozent (2009). Im gleichen Zeitraum nahm die Prävalenz der Hyperurikämie, also von Patienten mit Serum-Harnsäurewerten über $6 \mathrm{mg} / \mathrm{dl}$, von 8,5 auf 11,9 Prozent zu, berichtete Prof. Dr. Giovambattista Desideri aus dem italienischen L'Aquila. Schlechter sieht es in den USA aus, mit einer Hyperurikämie-Prävalenz von rund 22 Prozent. In China reiche die Spanne von 13 bis 25 Prozent, so Desideri beim europäischen RheumaKongress (EULAR) in Rom.
\end{abstract}

\section{Gesamtkosten eines Gicht- Patienten in den USA}

Mit der steigenden Prävalenz kommen steigende Kosten auf die Gesundheitssysteme zu, denn Gicht-Patienten sind teurer als vergleichbare Patienten ohne Gicht. Desideri zitierte eine US-Studie, in der die jährlichen Gesamtkosten eines Gicht-Patienten auf knapp 15.000 US-Dollar beziffert wurden. Vergleichbare Patienten ohne Gicht kamen nur auf gut 9.000 US-Dollar (J Manag Care Pharm. 2008;14:164). Noch teurer wird es, wenn die Gicht-Patienten Tophi aufweisen. Dann schlagen rund 23.000 Dollar Gesundheitskosten zu Buche, so der Internist bei einer von Menarini/Berlin-Chemie unterstützten Veranstaltung. Ein weiteres Ergebnis: Je häufiger die Patienten Gicht-Attacken haben, desto höher sind ebenfalls die Gesundheitskosten.

\section{Kosten in Europa}

Ähnliche Kostenverhältnisse gibt es auch in Europa. Das habe eine eige- ne, noch nicht publizierte Studie ergeben, sagte Desideri. Ausgewertet wurden darin Daten von über 110.000 Patienten, bei denen zumindest einmal der Harnsäurewert erfasst wurde (Degli Esposti L. et al., submitted). Mit steigenden Harnsäurewerten steigen dabei auch die Kosten: Liegt der Harnsäurespiegel im Serum unter $6 \mathrm{mg} / \mathrm{dl}$, wurden rund 2.750 Euro Gesamt-Gesundheitskosten ermittelt. Zwischen 6 und $7 \mathrm{mg} / \mathrm{dl}$ waren es fast 3.000 Euro, zwischen 7 und $8 \mathrm{mg} / \mathrm{dl}$ fast 3.400 und über $8 \mathrm{mg} / \mathrm{dl}$ gut 4.600 Euro. Ein Großteil dieser Kosten entfiel auf ambulante und stationäre Behandlungen. Diese lagen bei Personen mit SerumHarnsäurewerten unter $6 \mathrm{mg} / \mathrm{dl}$ bei 1.515 Euro und bei Werten über $8 \mathrm{mg} /$ dl bei knapp 3.100 Euro.

Bei den stationären Kosten gab es dabei eine deutliche Relation zwischen Harnsäurewerten und Krankenhauseinweisungen aufgrund von Nieren- und Herz-Kreislauf-Erkrankungen. Die Arzneimittelausgaben erhöhten sich im Vergleich zu den Gesamtkosten wesentlich geringer, nämlich nur von 642 auf 787 Euro.

Die meisten der erfassten Patienten erhielten zur harnsäuresenkenden Therapie Allopurinol, nur ein kleiner Teil bekam Febuxostat (Adenuric $^{\circledast}$ ). Desideri präsentierte hierzu eine erste Analyse: Zwar liegen die Arzneimittelkosten mit Febuxostat höher als mit Allopurinol, die Gesamtkosten seien jedoch 20 Prozent geringer. Der Grund: Die Kosten für die stationäre Versorgung waren bei den Patienten unter Febuxostat-Therapie deutlich geringer.

\section{Gicht und das Herz-Kreislauf- System}

An den Zusammenhang von Gicht und kardiovaskulären (CV) Ereignissen erinnerte Priv. Doz. Dr. Fernando Perez-Ruiz aus Barakaldo, Spanien. Vor allem wenn Patienten bereits kardiovaskuläre Risikofaktoren aufweisen, wirkten sich erhöhte Harnsäurewerte negativ auf das Herz-Kreislauf-System aus. Perez-Ruiz präsentierte bei der gleichen Veranstaltung eine eigene Studie, in der das CV-Risiko bei Gicht-Patienten mit der Schwere der Gicht-Erkrankung zunahm. Lag der Harnsäurewert zu Beginn zwischen 8,7 und 9,1 mg/dl, war die Sterberate um den Faktor 2,4 höher, bei Harnsäurewerten über 9,1 mg/ dl um das 3-fache. Das Vorliegen subkutaner Tophi wiederum verdoppelte das Sterberisiko während des Beobachtungszeitraums von 47 Monaten (Ann Rheum Dis 2014; 73: 177).

\section{Quelle:}

Satelliten-Symposium "Shaping the actual burden of hyperuricaemia with deposits", EULARKongress in Rom, 12. Juni 2015, Veranstalter: Menarini

\section{Dr. Michael Hubert}

rheuma plus $2015 \cdot 14: 61$

DOI 10.1007/s12688-015-0035-1

Online publiziert: 29. August 2015

(c) Springer-Verlag Wien 2015

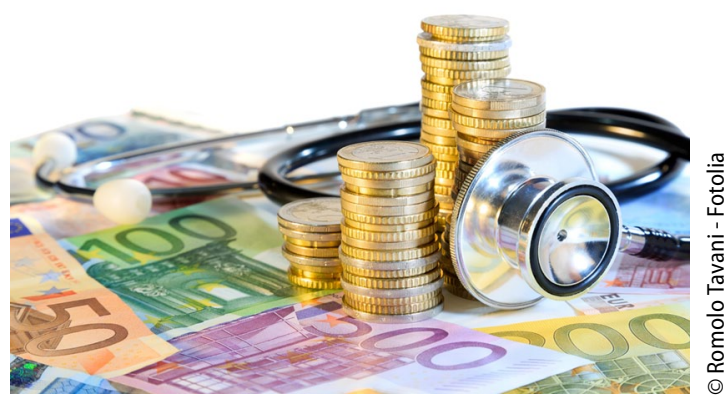

Gicht-Patienten verursachen mehr Kosten als Patienten ohne Gicht. 